\title{
Derek Richards to retire as Editor of EBD
}

Derek Richards has announced his retirement as Editor of EvidenceBased Dentistry, (EBD), after 20 years at the helm of the journal.

After qualifying from Cardiff Dental School in 1977 Derek worked in hospital, general and community dental practice. While undertaking dental public health training in the Anglia and Oxford Region he developed an interest in evidence-based health care and, in 1995, helped to establish the Centre for Evidencebased Dentistry. He has been involved with teaching evidencebased dentistry and a wide range of evidence-based initiatives both nationally and internationally since then. In 1998 he was instrumental in founding $E B D$, which he has edited since then, overseeing the production of 19 volumes and over 70 issues of the journal.

Derek currently holds the posts of Honorary Senior Lecturer at Dundee and Glasgow Dental Schools, Consultant in Dental Public Health with Forth Valley Health Board and Director of the Centre for Evidence-based Dentistry at the Dental Health Services Research Unit, University of Dundee. He is a specialist advisor to the Scottish Dental Clinical Effectiveness Programme and led the development of the Scottishdental.org website and has recently completed the development of an online training programme for the Scottish National Dental Epidemiology programme (www.ndip. scottishdental.org).
Derek was involved in the York Review of water fluoridation and the NICE dental recall guideline and chaired a selective update of the SIGN guideline on the prevention of caries in children, which was published in March 2014. He is also a co-author of the book Evidencebased Dentistry: Managing Information for Better Practice (Quintessential of Dental Practice).

The British Dental Association and Springer Nature wish to express their thanks to Derek for his tireless work as Editor of $E B D$ over many years and for his significant contributions to the field of evidence-based dentistry.

Stephen Hancocks, Editor-in-Chief of the BDJ Portfolio, said 'In many ways it seems as if Derek not only started Evidence-based Dentistry, but actually embodies it! As Editor-in-Chief I am enormously grateful to Derek for all his work on the title, as is the BDA, but further, I would like to take this opportunity to acknowledge his stature in this field and the huge contribution he has made to the accessibility and application of research. I wish him all the very best for the future without the requirement to provide any evidence whatsoever that it is well-deserved, long, happy and healthy.'

\section{Call for applications: Editor, Evidence-Based Dentistry}

The British Dental Association and Springer Nature invite applications for the post of Editor of Evidence-Based Dentistry.

\section{Responsibilities}

The Editor is responsible for ensuring the timely and efficient publication of Evidence-Based Dentistry. Key responsibilities include:

- Selecting papers to be summarised and evaluated in the journal

- Identifying suitably qualified authors to write summaries

- Allocating papers to authors and ensuring that completed summaries are delivered on schedule

- Ensuring that completed copy is supplied to the EBD production team to agreed standards and on schedule

- Recruiting and supervising Deputy Editors.

With the guidance of the Editorial Board, the editor is also responsible for:

- Determining editorial policies, processes and standards

- Growing the impact and reach of the journal.

\section{Person specification}

The successful candidate will be able to demonstrate:

- A significant academic reputation and strong publication record in evidence-based dentistry

- An understanding of the aims and audience of the journal

- Fairness, objectivity and integrity

- The administrative skills necessary to run the journal

- The ability to integrate the duties of editor alongside other commitments.
Editorial experience as either an Editor or Associate Editor would be advantageous.

\section{About the journal}

Evidence-Based Dentistry delivers the best available evidence on the latest developments in oral health, evaluating the evidence and providing guidance concerning the value of the authors conclusions. It aims to keep dentistry up to date with new approaches, exploring a wide range of the latest developments through an accessible expert commentary. Original papers and relevant publications are condensed into digestible summaries, drawing attention to the current methods and findings.

Evidence-Based Dentistry is published by Springer Nature on behalf of the British Dental Association.

\section{Application process}

Applications should include:

1. A full academic CV

2. A statement of editorial vision, explaining why the applicant wishes to become editor and how the applicant would change, develop and improve the journal

3. Any other factors that would support the application.

An editorial stipend is available for this post.

The closing date for applications is $31^{\text {st }}$ December 2018 .

Please send applications by email, in PDF format, to James Sleigh (james.sleigh@springernature.com). 